OPEN ACCESS

Edited by:

Ben Nephew,

Worcester Polytechnic Institute,

United States

Reviewed by:

Meghan Elizabeth Flanigan,

University of North Carolina at Chapel

Hill, United States

Jamie Maguire,

Tufts University School of Medicine,

United States

*Correspondence:

Qingchun Tong

qingchun.tong@uth.tmc.edu

Specialty section:

This article was submitted to

Neuroendocrine Science,

a section of the journal

Frontiers in Neuroscience

Received: 15 December 2020

Accepted: 01 March 2021

Published: 19 March 2021

Citation:

Young CE and Tong Q (2021)

Corticotropin Releasing Hormone

Signaling in the Bed Nuclei of the Stria

Terminalis as a Link to Maladaptive

Behaviors.

Front. Neurosci. 15:642379.

doi: 10.3389/fnins.2021.642379

\section{Corticotropin Releasing Hormone Signaling in the Bed Nuclei of the Stria Terminalis as a Link to Maladaptive Behaviors}

\author{
Claire Emily Young ${ }^{1}$ and Qingchun Tong 1,2,3*
}

${ }^{1}$ The Brown Foundation Institute of Molecular Medicine, The University of Texas Health Science Center at Houston, Houston, TX, United States, ${ }^{2}$ Department of Neurobiology and Anatomy of McGovern Medical School, The University of Texas Health Science Center at Houston, Houston, TX, United States, ${ }^{3}$ MD Anderson Cancer Center \& UTHealth Graduate School of Biological Sciences, The University of Texas Health Science Center at Houston, Houston, TX, United States

The bed nuclei of the stria terminalis (BST) is a limbic region in the extended amygdala that is heavily implicated in anxiety processing and hypothalamic-adrenal-pituitary (HPA) axis activation. The BST is complex, with many nuclei expressing different neurotransmitters and receptors involved in a variety of signaling pathways. One neurotransmitter that helps link its functions is corticotropin releasing hormone $(\mathrm{CRH})$. BST CRH neuron activation may cause both anxiogenic and anxiolytic effects in rodents, and $\mathrm{CRH}$ neurons interact with other neuron types to influence anxiety-like responses as well as alcohol and drug-seeking behavior. This review covers the link between BST $\mathrm{CRH}$ neurons and thirteen other neurotransmitters and receptors and analyzes their effect on rodent behavior. Additionally, it covers the translational potential of targeting $\mathrm{CRH}$ signaling pathways for the treatment of human mental health disorders. Given the massive impact of anxiety, mood, and substance use disorders on our society, further research into BST $\mathrm{CRH}$ signaling is critical to alleviate the social and economic burdens of those disorders.

Keywords: BNST, CRH, CRHR1, extended amygdala, anxiety, addiction

\section{INTRODUCTION}

Approximately one in three people in the United States will develop an anxiety disorder during their lifetime (Craske et al., 2017). The bed nuclei of the stria terminalis (BST; also known as BNST) is a small, sexually dimorphic, heterogeneous region that in the past 20 years, has been highlighted for its role in stress and anxiety responses (for review, see Lebow and Chen, 2016). While traditionally BST research has focused on anxiety processing, in recent years the BST has been increasingly implicated in dysregulated signaling patterns consistent with many mental health disorders in both animal models and humans (Gungor and Paré, 2016; Lebow and Chen, 2016; Luyten et al., 2016; Blomstedt et al., 2017; Knight and Depue, 2019). Given the economic and social burden of those disorders on our society today, further study of the BST is a key step in the development of more effective treatments.

The BST circuitry is complex, involving neural connections both between the BST and other brain regions, and within the different nuclei of the BST. The BST connectivity has been discussed 
extensively elsewhere (see Bota et al., 2012; Vranjkovic et al., 2017; Ch'ng et al., 2018) and will not be elaborated upon in detail here. In brief, the BST is commonly grouped with the amygdala as part of the extended amygdala because of their proximity and similar cellular composition and immunohistochemistry (Alheid and Heimer, 1988). The two regions are also connected through signaling circuits like that of corticotropin releasing hormone (CRH; also known as $\mathrm{CRF}$ ) between the central amygdala (CEA) and anteromedial BST (BSTam) (Pomrenze et al., 2019). More recent studies have demonstrated a role for the BST in anxiety processing independent of amygdalar inputs, and they underscore the need for more research specifically focusing on the BST.

Preclinical models are important for advancing the understanding of mental health disorders because they allow for the precise modification of animal brains. Previous research has demonstrated that the BST is involved in the processing of anxiety-like behavior in animal models, characterized by sustained fear due to conditioned or unpredictable cues (Walker and Davis, 1997; Walker et al., 2003; Daldrup et al., 2016), while the amygdala is more involved in the processing of phasic fear induced by short, discrete cues (Davis et al., 2010). The distinction that animals display anxiety-like behavior, and not anxiety, is necessary since their behavior is measured using metrics that are assumed to represent anxiety in animals, such as time spent in the center of an open field (OF) test (Carola et al., 2002), but cannot be confirmed to truly represent anxiety since anxiety as traditionally conceptualized is a subjective state (LeDoux and Pine, 2016). The term "anxiety-like" acknowledges that attributing behaviors to anxiety in animals is a form of anthropomorphism and may not be accurate.

An additional nuance to BST research is the distinction between anxiety and fear. The terms "fear" and "anxiety" are often used interchangeably, both in popular culture and by scientists and medical professionals, and Shackman and Fox (2016) argue that saying "fear and anxiety" together in reference to either will allow for less confusion about the term while focusing on the threat context. However, included in the threat context is the threat imminence, and other researchers such as Gungor and Paré (2016) argue that fear can be categorized as a defensive response to an imminent threat, while anxiety is a response to a diffuse, or not imminent threat. The majority of papers referenced in this review focus on what would be classically considered as anxiety-like responses. While early models created a sharp distinction between the CEA and BST in fear and anxiety processing, more recent research has demonstrated that both regions have a role in processing both uncertain and certain threat contexts, and thus may influence fear and anxiety processing (Shackman and Fox, 2016).

The BST is involved in the development of other maladaptive behaviors beyond anxiety disorders. It has been implicated in binge drinking and alcohol use disorders (AUDs), particularly the stress-induced reinstatement of drug-seeking behaviors (Silberman and Winder, 2013; Nentwig et al., 2019; Snyder et al., 2019). In this model of the addiction cycle, withdrawal produces negative affect and dysregulated BST CRH signaling. Stress can then induce the reinstatement of drug-seeking behavior (for review, see Silberman and Winder, 2013). The BST is also involved in the regulation of depressive-like behaviors, an effect that is CRH-dependent (Salimando et al., 2020). Depressive-like behavior is typically quantified in preclinical models by tests such as the forced swim (FS) and tail suspension tests that measure parameters like helplessness and anhedonia (Krishnan and Nestler, 2011). Finally, several results discussed in this review implicate BST circuits in the regulation of feeding behavior. In humans, feeding behavior is psychologically complex and not driven solely by the demands of energy metabolism, and thus may be difficult to investigate in preclinical models, particularly in relation to maladaptive behaviors (Ellacott et al., 2010). The link between the BST and maladaptive behaviors beyond anxiety is an emerging field of research, and CRH signaling within the BST presents new treatment targets for these behaviors.

Because of the demonstrated impact of CRH on rodent behavior and its interaction with many other neurotransmitters and neuron types, this review will examine stress processing in the BST through the lens of CRH signaling and how it affects animal behavior, as well as possible implications of BST manipulation on the treatment of human mental health disorders. Figure $\mathbf{1}$ and Table $\mathbf{1}$ provide an overview of the effects discussed in this review.

\section{BST NOMENCLATURE AND ANATOMY}

Papers vary in their usage of BST or BNST, as well as nucleus or nuclei in the BST name. Here, usage of the BST acronym and the word "nuclei" instead of "nucleus" in the BST name is to remain consistent with atlas nomenclature (Swanson, 2004; Lein et al., 2007; Shackman and Fox, 2016) and acknowledge the different functions of the BST nuclei. While the accepted number of BST nuclei varies (Gungor and Paré, 2016), this review will use the standard nomenclature system established by the Swanson (2004) rat brain atlas, which includes sixteen different regions, defined mostly by cytoarchitecture (Ju and Swanson, 1989). This is also the nomenclature used by the Allen Reference Atlases, with minor differences in hierarchical structure that include the removal of the cell sparse zone (BSTsz) and premedullary nucleus (BSTpm) as BST nuclei (Lein et al., 2007). Both the Swanson (2004) rat brain atlas and the Allen Mouse Brain Atlas (2004) divide the BST into two major subparts-the anterior and posterior divisions-with most research on stress and anxiety focusing on the anterior division (Kim et al., 2013). Important subdivisions for stress processing include the BSTam, oval nucleus BST (BSTov), dorsomedial nucleus BST (BSTdm), ventral nucleus BST (BSTv), and the anterolateral BST (BSTal) from the anterior division, and the dorsal BST (BSTd) from the posterior division.

Despite the existence of this standard nomenclature system, BST nomenclature is highly inconsistent across papers. This makes it difficult to compare data from paper to paper (Shackman and Fox, 2016), and because of the large number of nuclei in the BST (Gungor and Paré, 2016), accurate labeling and nomenclature is critical for reproducible and easily understood results. For example, if different papers call the anteromedial BST 


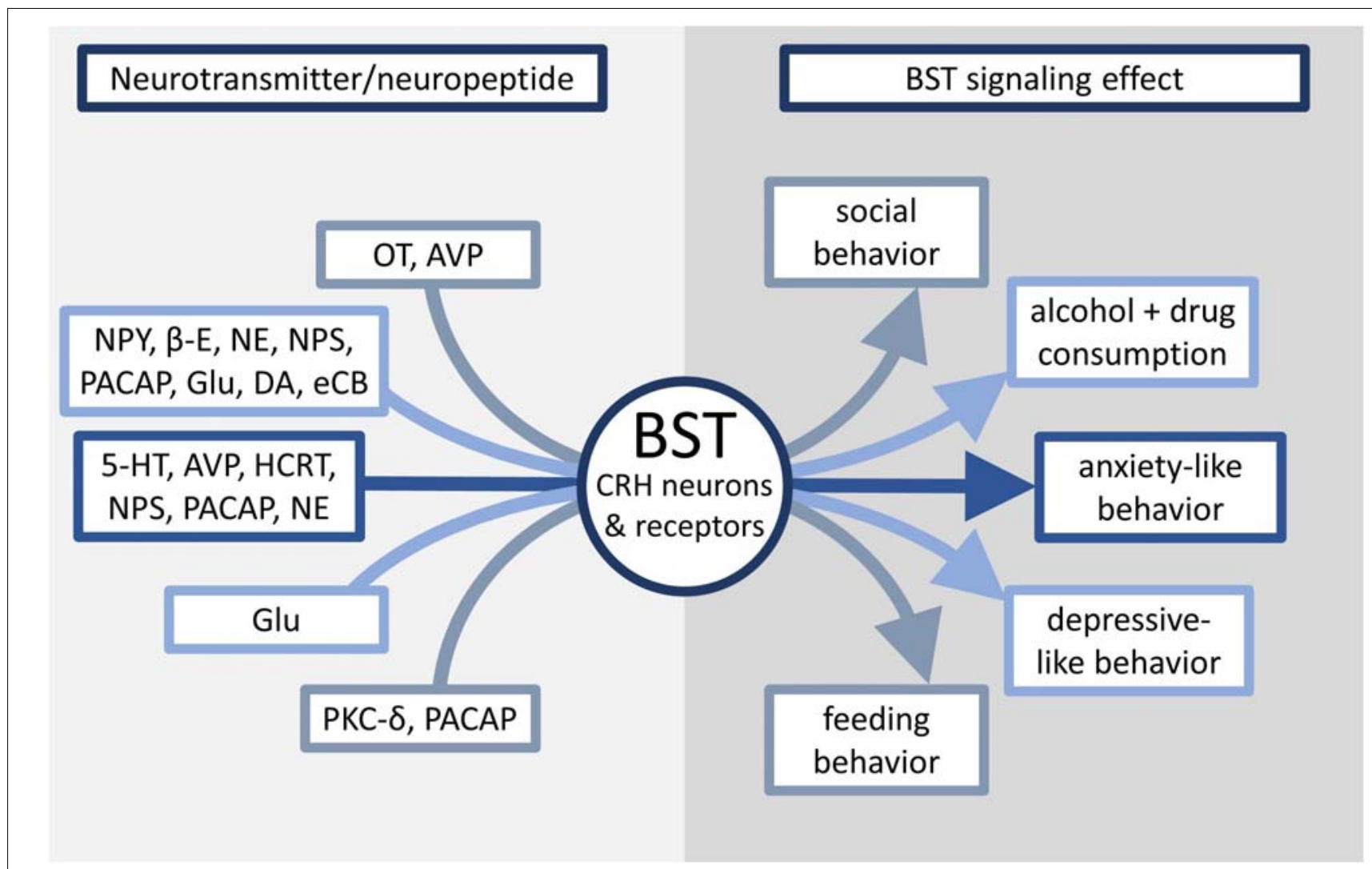

FIGURE 1 | Overview of neurotransmitters linked to $\mathrm{CRH}$ signaling in the BST and their effects on maladaptive behaviors.

the anterodorsal, anteroventral, or dorsolateral BST, it is difficult for readers to determine if the papers focus on the same area. When discussing results from various papers, this review uses the same nuclei classification as used by the original authors. Figure 2 provides an illustration of the BST nuclei, as well as different nomenclatures used by the papers referenced in this review.

\section{OVERVIEW OF CRH SIGNALING IN THE BST}

Classically, CRH neurons are thought of in their role in hypothalamic-pituitary-adrenal (HPA) axis activation. In this role, there are at least two different populations of distinct $\mathrm{CRH}$ neurons-those in the BST and those in the paraventricular nucleus of the hypothalamus (PVH) (Dabrowska et al., 2013). The BST has been shown to contain mostly GABAergic neurons and a small amount of glutamatergic neurons (Moga and Saper, 1994). Similarly, CRH neurons in the BST are primarily GABAergic (Veinante et al., 1997), with Dabrowska et al. (2013) finding that $95 \%$ of $\mathrm{CRH}$ neurons in the BSTov colocalized with glutamic acid decarboxylase 67, a marker of GABAergic neurons, and had low colocalization with vesicular glutamate transporter 2, a marker of glutamatergic neurons. Conversely, PVH CRH neurons are primarily glutamatergic (Dabrowska et al., 2013), suggesting a unique role for each of the two populations in HPA axis activation. BST CRH neurons are concentrated in the BSTov (Ju et al., 1989), which is critical for the regulation of anxiety states (Kim et al., 2013) and may have a role as the master controller of the BST (Ch'ng et al., 2018).

Corticotropin releasing hormone signaling in the BST includes $\mathrm{CRH}$ neurons as well as the $\mathrm{CRH}$ receptors, which are widely distributed in the BST (Van Pett et al., 2000). CRH binding to $\mathrm{CRH}$ receptor type 1 (CRHR1) or $\mathrm{CRH}$ receptor type 2 (CRHR2) causes the receptor to couple to a $\mathrm{G}_{\mathrm{s} \alpha}$ protein, which then stimulates cAMP production through adenylate cyclase activation. cAMP activates protein kinase A (PKA), which phosphorylates downstream targets to carry out the effects of CRH signaling (for review, see Hillhouse and Grammatopoulos, 2006). Despite the prevalence of CRH neurons and receptors in the BST, in the anterolateral cell group of the BST (BSTalg), Dabrowska et al. (2013) found virtually no colocalization between CRH neurons and CRHR1 or CRHR2-expressing neurons.

$\mathrm{CRH}$ infusion to the BST was found to increase anxietylike behavior in rats in the elevated plus maze (EPM) test, an effect mediated through CRHR1s (Sahuque et al., 2006). BST $\mathrm{CRH}$ infusion was also found to induce the reinstatement of cocaine-seeking behavior (Erb and Stewart, 1999), demonstrating the effect of $\mathrm{CRH}$ signaling on multiple forms of maladaptive behaviors. An important source of CRH in the BST comes from CRH projections from the CEA to the dorsolateral BST (BSTdl), and those projections are necessary for the induction 
TABLE 1 | Summary of BST-CRH signaling studies.

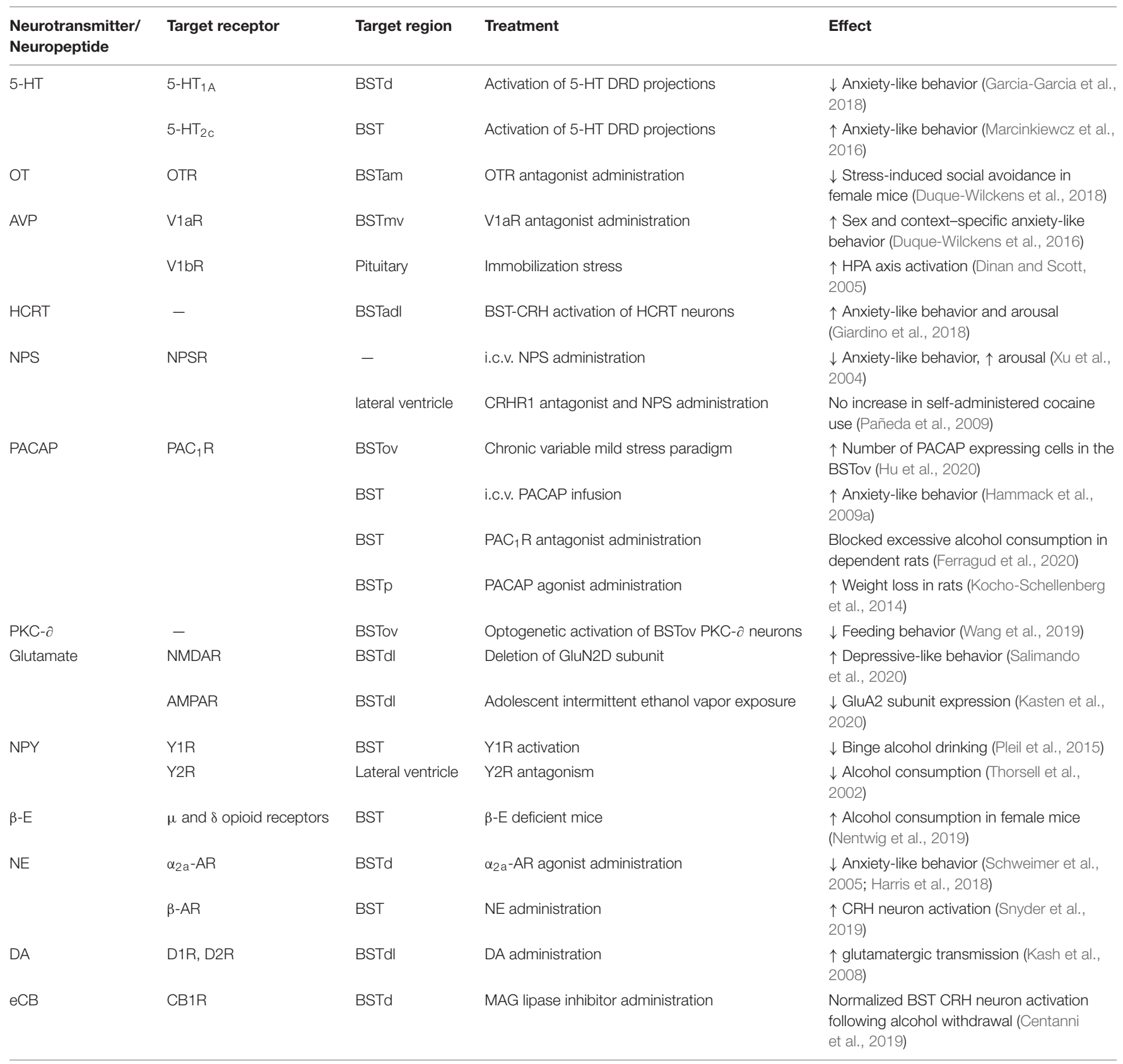

-Indicates value not specified by cited paper.

of stress-induced anxiety (Pomrenze et al., 2019). In support of this conclusion, Ventura-Silva et al. (2020) found that CRH knockdown in the CEA reduced stress-induced anxiety-like behavior in rats and had no effect on the results of a fearpotentiated startle paradigm. This reinforces the role of CEABST circuit signaling in mediating chronic, and not acute, stress processing.

Hu et al. (2020) found that a chronic variable mild stress paradigm resulted in increased phosphorylated PKA in the anterior dorsolateral BST (BSTadl). Infusion of mice with a PKA-selective antagonist, H89, attenuated the anxiogenic effects caused by the stress paradigm, as measured by the EPM, OF, novelty suppressed feeding (NSF) tests. This suggests that PKA is necessary for transmitting anxiogenic signals caused by CRHR1 activation in the BSTov.

While many studies have linked BST activity and CRH signaling to anxiogenic activity, especially anxiogenic activity induced by CRHR1 activation (Bale and Vale, 2004), Henckens et al. (2017) found that CRHR2 activation is necessary for attenuating the stress response and promoting stress recovery. CRHR2 is highly expressed in the posterior BST (BSTp) (Van Pett et al., 2000), and optogenetic activation of CRHR2 neurons 
= BSTdl (Kasten et al., 2020)

= BSTdl (Kash et al., 2008; Salimando et al., 2020)

= BSTmv (Duque-Wilckens et al., 2016)

= BSTalg (Dabrowska et al., 2013)

$$
\begin{aligned}
& \text { ᄂ I = BSTVl (Wang et al., 2019) }
\end{aligned}
$$

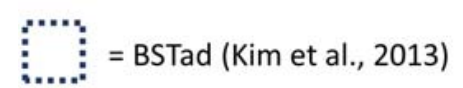
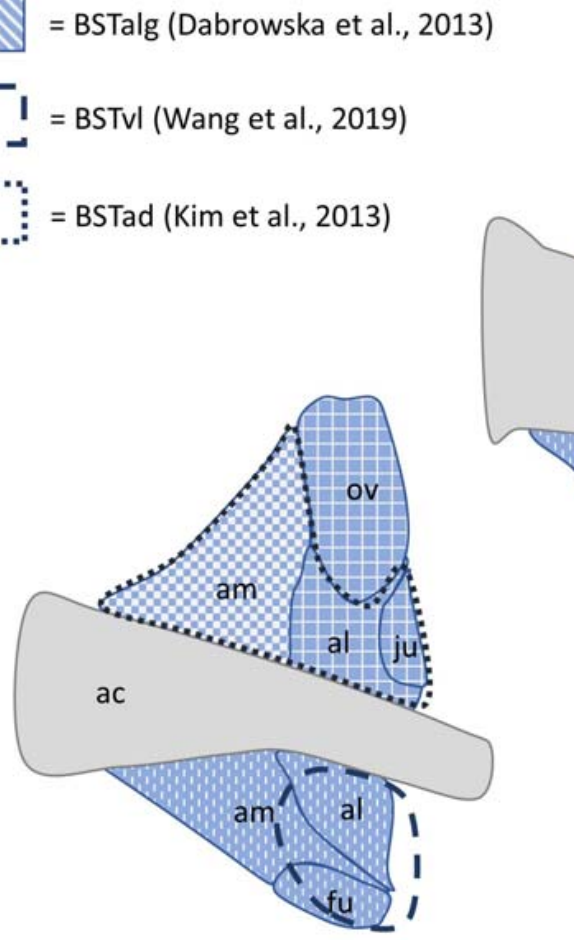
(2004) found that activation of the BSTal by DRD 5-HT inputs caused hyperpolarization and inhibition with anxiolytic effects, measured by the acoustic startle reflex. DRD 5-HT neurons are activated by CRH (Lowry et al., 2000), and because of the high density of CRH in the BST, it was questioned if 5-HT and CRH signaling between the DRD and BST formed a feedback loop.

In support of this, Donner et al. (2018) found that rat Tph2, the rate-limiting enzyme of 5-HT synthesis, and tph 2 mRNA expression in the DRD were increased after stress exposure. Infusion of the BST with urocortin-1 (Ucn-1), a CRHR1 and CRHR2 agonist (Vaughan et al., 1995), was shown by Donner et al. (2020) to increase DRD tph2 mRNA, suggesting that DRD serotonergic neurons are regulated by BST-CRH neurons and help promote anxiety-like states. Optogenetic activation of 5-HT projections from the DRD to the BSTd resulted in reduced c-fos expression and anxiolytic effects on behavior in the EPM, OF, and NSF tests, while inhibition had anxiogenic effects, mediated through $5-\mathrm{H}_{1 \mathrm{~A}}$ receptors in the BSTd (Garcia-Garcia et al., 2018).

Marcinkiewcz et al. (2016) found that activation of DRD projections to the $\mathrm{BST}$, operating through $5-\mathrm{HT}_{2} \mathrm{C}$ receptors, was anxiogenic in the EPM and NSF tests and silenced anxiolytic BST outputs to the ventral tegmental area (VTA) and lateral hypothalamus $(\mathrm{LH})$. The different 5 -HT receptor families might explain the opposing effects found by Donner et al. (2020) and Garcia-Garcia et al. (2018). However, a knockdown model of the $5-\mathrm{HT}_{1 \mathrm{~A}}$ receptor yielded no effect on anxiety-like behavior, suggesting that without activation, the receptor may not be in great enough abundance to yield a physiologically relevant effect on behavior (Marcinkiewcz et al., 2019). More research is therefore necessary to further elucidate the role of 5$\mathrm{HT}_{1 \mathrm{~A}}$ receptors in regulating anxiety-like behavior, especially considering the implications of the $5-\mathrm{HT}_{1 \mathrm{~A}}$ receptor on SSRI treatment success (Quentin et al., 2018).

\section{OXYTOCIN}

Oxytocin (OT), beyond acting as a hormone, plays a role in the regulation of anxiety processing in the central nervous system and has been the subject of several thorough reviews (Janeček and Dabrowska, 2019; Steinman et al., 2019). OT is primary synthesized in the PVH and supraoptic nuclei of the hypothalamus, and while some of those neurons project to the BST and act as a source of OT, OT is also synthesized in the BST itself (Lee et al., 2009). Intraperitoneal OT administration has been found to have anxiolytic effects in rats, measured by the emergence and social interaction (SI) tests, as well as decrease alcohol consumption (Bowen et al., 2011). The $\mathrm{G}_{\mathrm{q}}$ proteincoupled OT receptors (OTRs) in the BSTam have also been linked to social avoidance in female, but not male, mice, again highlighting the sexual dimorphism of the BST (Duque-Wilckens et al., 2018). More specifically, Dabrowska et al. (2011) found that OT-immunoreactive (ir) fibers in the BSTov colocalized with CRHR2-ir fibers and had perisomatic contact with CRH-ir neurons. These neurons project to the magnocellular portion of the PVH (Dong et al., 2001), forming a reciprocal feedback loop to regulate activation of the HPA axis (Dabrowska et al., 2011).

\section{ARGININE VASOPRESSIN}

Like OT, changes to arginine vasopressin (AVP) signaling in the medioventral BST (BSTmv), including expression of AVP and its receptor, the $\mathrm{G}_{\mathrm{q}}$ protein-coupled vasopressin V1a receptor (V1aR), have been implicated in sex-specific responses to social defeat and stress (Duque-Wilckens et al., 2016). The BST is a major extrahypothalamic source of AVP, and BST AVP neurons project to many forebrain and midbrain structures (Leeuwen and Caffé, 1983; de Vries and Miller, 1999). Administration of a V1aR antagonist to the BSTmv had anxiogenic effects in both male and female mice in the SI test, but in female mice, the effect only occurred in social contexts (Duque-Wilckens et al., 2016). AVP works with $\mathrm{CRH}$ to regulate the HPA axis (Kormos and Gaszner, 2013), and sustained AVP levels due to chronic stress, operating through $\mathrm{G}_{\mathrm{q}}$ protein-coupled $\mathrm{V} 1 \mathrm{~b}$ receptors (V1bRs; also known as V3R), lead to increased HPA activation through the stimulation of adrenocorticotropin $(\mathrm{ACTH})$ release (Dinan and Scott, 2005). Given the role of $\mathrm{CRH}$ neurons in HPA axis activation and the presence of V1bRs in the BST (Hernando et al., 2001), it is possible that BST AVP signaling, mediated through CRH signaling, is involved in multiple pathways, including the processing of anxiogenic stimuli and HPA axis activation. Clinically, elevated AVP levels have been seen in depressed patients, and V1bR antagonists are being investigated in preclinical models for their antidepressant and anxiolytic effects (for review, see Alldredge, 2010).

\section{HYPOCRETIN}

Hypocretin (HCRT; orexin) is expressed in a subset of LH neurons and is implicated in the regulation of emotional behavior (Soya and Sakurai, 2020). HCRT-LH neurons receive inputs from CRH-BST neurons, and HCRT activation via CRH-BST neurons is associated with negative valence and behavioral avoidance in the real-time place test (Giardino et al., 2018). HCRT is closely associated with wakefulness and narcolepsy (Soya and Sakurai, 2020) because of its role in the regulation of vigilance and arousal states (Boutrel and de Lecea, 2008), so it raises the question of if the BST-HCRT-LH pathway can help explain the sleep disruptions commonly associated with anxiety (American Psychiatric Association, 2013). It is possible that upregulation of CRH neurons in the BST and subsequent activation of HCRTLH neurons may therefore contribute to the increased arousal states associated with anxiety and other altered mood states, as well as contribute to the role of the BST in regulating addiction (Snyder et al., 2019).

\section{NEUROPEPTIDE S}

Neuropeptide $S$ (NPS) and its receptor, the $G_{s} / G_{q}$ proteincoupled NPS receptor (NPSR; also known as GPR154), make up a deorphanized GPCR system implicated in the regulation of anxiety, arousal, and wakefulness (Xu et al., 2004), as well as drug and alcohol-related behaviors (Cannella et al., 2009; 
Pañeda et al., 2009). While NPS is expressed in only a few regions of the rat brain, notably in a group of neurons between the locus coeruleus and Barrington's nucleus (Xu et al., 2007), the NPSR is more widely distributed and is found in the BSTV (Leonard and Ring, 2011). Administration of NPS in rodents resulted in increased arousal, determined by locomotor activity, and decreased anxiety-like behavior, determined by the EPM, OF, and light-dark box tests (Xu et al., 2004), similar to the effect of nicotine (Koob and Greenwell, 2004). Pañeda et al. (2009) found that in mice, i.c.v. administration of NPS to the lateral ventricle induced cocaine-seeking behavior in a CRHR1dependent manner. When they either administered the CRHR1 antagonist antalarmin or used a CRHR1 knockout model, NPS administration failed to increase self-administered cocaine use. Following morphine withdrawal, NPSR transcript prevalence decreased in the BST, and NPS administration decreased anxietylike behavior associated with withdrawal (Ghazal et al., 2013). NPS has also been linked to LH-HCRT neurons (Cannella et al., 2009), further linking the BST and CRH signaling to addiction pathways as discussed in the previous HCRT section.

\section{PITUITARY ADENYLATE CYCLASE-ACTIVATING POLYPEPTIDE}

Pituitary adenylate cyclase-activating polypeptide (PACAP), operating through the $\mathrm{G}_{\mathrm{s}} / \mathrm{G}_{\mathrm{q}}$ protein-coupled $\mathrm{PAC}_{1}$ receptor $\left(\mathrm{PAC}_{1} \mathrm{R}\right)$ (Pisegna and Wank, 1996), is an upstream regulator of $\mathrm{CRH}$ that innervates $\mathrm{CRH}$ neurons in the BSTov, where it contributes to increased anxiety states and can activate the HPA axis (for review, see Lebow and Chen, 2016). Major sources of PACAP to the BST include the PVH and dorsal vagal complex (Kozicz et al., 1998). Hu et al. (2020) found that subjecting male mice to a chronic variable mild stress paradigm significantly increased the number of PACAP expressing cells in the BSTov, as well as Pacap mRNA expression in the BSTadl. Effects on anxiety-like behavior in male rats following PACAP infusion into the BST, measured by the light-enhanced startle test, are long lasting, occurring for at least 1 week post infusion (Hammack et al., 2009a). The anterodorsal BST (BSTad) had been previously shown to have anxiolytic effects (Kim et al., 2013), highlighting the heterogeneity and complexity of the BST.

While classically PACAP has been thought of in terms of its regulation of anxiety-like behavior, recently it has also been implicated in the regulation of alcohol consumption. Ferragud et al. (2020) demonstrated that exposure of rats to chronic intermittent ethanol vapors increased PACAP levels in the BST, and that administration of a $\mathrm{PAC}_{1} \mathrm{R}$ antagonist to the BST blocked excessive alcohol consumption in ethanoldependent rats. This research highlights the diverse natures of neurotransmitters in the BST and how they may have multifaceted roles in behavioral regulation.

Additionally, PACAP has been implicated in feeding regulation, with Kocho-Schellenberg et al. (2014) finding that infusion of the BSTp with a PACAP agonist resulted in a dosedependent weight loss for the $24 \mathrm{~h}$ following the infusion in both male and female rats.
Susceptibility to the anxiogenic effects of PACAP depends on previous stress exposure, as well as sex (King et al., 2017). Female rats did not display the same increase in startle reflex as male rats when infused with PACAP in the BST following chronic stress exposure (King et al., 2017). More research is needed to investigate the effects of PACAP expression in female rodents. This is especially important considering that PACAP has been implicated as a potential treatment target for PTSD (Lebow and Chen, 2016), and that women are more than twice as likely as men to develop PTSD following a traumatic event (King et al., 2017).

\section{PROTEIN KINASE C DELTA}

The BSTov contains protein kinase $\mathrm{C}$ delta (PKC- $\partial$ ) neurons, which help mediate feeding behaviors through a novel circuit proposed by Wang et al. (2019). The PKC family is composed of ten different isoforms that are sorted into three subfamilies, with PKC- $\partial$ belonging to the novel PKC subfamily (SanchezBautista and Nicolas, 2013). PKC- $\partial$ is activated when CRH binds to the CRHR1 or CRHR2 receptor, which can then couple to a $G_{\mathrm{q}}$ protein and activate phospholipase $\mathrm{C}$ (PLC). PLC then catalyzes the production of inositol trisphosphate (IP3) and diacylglycerol (DAG), which activates PKC- $\partial$. Activating BSTov PKC- $\partial$ neurons suppressed feeding in mice, while silencing those neurons increased feeding (Wang et al., 2019). BSTov PKC- $\partial$ neurons innervate and inhibit ventrolateral BST (BSTvl) neurons, demonstrating the interconnectivity of the BST subnuclei (Wang et al., 2019). Those BSTvl neurons then project to the LH to promote feeding behaviors, which explains how activating BSTov PKC- $\partial$ neurons suppresses feeding by inhibiting the BSTvl neurons that are necessary to activate the LH neurons (Wang et al., 2019). PKC- $\partial$ and CRH signaling may therefore link anxiety-like and feeding behaviors-in support of this conclusion, Hu et al. (2020) found that chronically stressed mice had decreased weight gain compared to controls.

\section{GLUTAMATE}

Glutamate operates though receptors that can be classified as either ionotropic, composed of $N$-methyl-D-aspartate receptors (NMDARs) and $\alpha$-amino-3-hydroxy-5-methyl-4isoxazolepropionic acid receptors (AMPARs), or metabotropic, and BST neurons contain both (Gracy and Pickel, 1995; Grueter and Winder, 2005; Grueter et al., 2006). Specifically, BST CRH neurons express NMDARs containing the GluN2D subunit (Salimando et al., 2020). NMDARs have been previously implicated in mental health disorders and their treatments (Ghasemi et al., 2014), and consistent with that, Salimando et al. (2020) found that deletion of the BST-GluN2D subunit led to increased depressive-like behaviors in mice as measured by the FS test, potentially because of decreased BST excitatory synaptic potentiation and subsequent increased excitatory drive onto BST-CRH neurons. There was no change in anxiety-like behavior, measured by the OF and elevated zero maze tests. GluN2D receptors were found to be localized in the BST to 
the BSTdl (Salimando et al., 2020), possibly contributing to the role of the BSTd in negative affect and valence processing (Kim et al., 2013). This research demonstrates the role of the BST in regulating emotional behavior beyond chronic fear responses and connects it to the regulation of mood disorders, such as major depressive disorder (MDD). Showing the translational potential between pre-clinical models and human studies, NMDAR antagonists are being investigated in clinical trials for the treatment of MDD and bipolar disorder (Ghasemi et al., 2014), and in 2019, the United States Food and Drug Administration (FDA) approved Spravato (esketamine), a NMDAR antagonist, in a nasal spray format for use in conjunction with antidepressants for the treatment of treatmentresistant depression (Daly et al., 2019; Popova et al., 2019; US Food and Drug Administration, 2019). However, concerns have been raised about the treatment length and long-term effects of intranasal esketamine treatment (Schatzberg, 2019; Zheng et al., 2020), and additional clinical trials will be key for improving MDD treatment using esketamine.

Bed nuclei of the stria terminalis neurons also contain AMPARs, a type of excitatory ionotropic glutamate receptor made up of four different subunits, GluA1-GluA4 (for review, see Chater and Goda, 2014). Kasten et al. (2020) found that adolescent intermittent ethanol vapor exposure (AIE) reduced the GluA2 AMPAR subunit expression in the BSTdl. They also found that the mGluR1 antagonist DHPG decreased long term depression in female, but not male, mice treated with AIE. CRHR1 activation resulting in PKA activation in the BST has been shown to cause the phosphorylation of GluR1 AMPAR subunits ( $\mathrm{Hu}$ et al., 2020), so while the glutamate receptor research discussed above was not directly linked to $\mathrm{CRH}$ neurons, considering the previous connections made between $\mathrm{CRH}$ neurons in the BST with both AUDs and MDD, it is possible that $\mathrm{CRH}$ neurons influence this phenomenon and remains an area for future exploration.

\section{NEUROPEPTIDE Y}

Neuropeptide Y (NPY) signaling has been implicated in alcohol abuse disorders (Pleil et al., 2015), feeding regulation (Higuchi, 2012), and fear memory (Bartsch et al., 2020). The majority of NPY input to the BST comes to the BSTa from agoutirelated protein (AgRP) neurons in the arcuate nucleus (ARC) that co-release NPY, although the BST also contains NPY interneurons (Betley et al., 2013; Kash et al., 2015). The $\mathrm{G}_{\mathrm{i} / \mathrm{o}}$ protein-coupled NPY receptor (NPYR) family has five receptors, although only four are active in humans, and NPYR activation frequently results in inhibition of adenylyl cyclase and cAMP accumulation (Pedragosa Badia et al., 2013). Since CRH causes cAMP production, NPY and CRH often have opposing effects on behavior. In fact, while $\mathrm{CRH}$ signaling in the BST promotes alcohol seeking-behaviors (Nentwig et al., 2019), Pleil et al. (2015) found that activation of the Y1 NPY receptor (Y1R) reduced binge alcohol drinking in mice without modifying anxiety-like behavior in the OF test. They demonstrated that Y1R activation inhibited PKA activity and increased the frequency of inhibitory postsynaptic currents in BST CRH neurons, suggesting that Y1R activation results in the inhibition of $\mathrm{CRH}$ signaling. However, signaling through the Y2 NPY receptor (Y2R), which is also coupled to a $\mathrm{G}_{\mathrm{q}}$ protein (Misra et al., 2004), has been demonstrated to have the opposite effect, with Thorsell et al. (2002) finding that administration of a Y2R antagonist to the lateral ventricle in rats decreased alcohol consumption. For further discussion about NPY's role in alcohol consumption, see Ch'ng et al. (2018).

\section{$\beta$-ENDORPHIN}

$\beta$-endorphin ( $\beta$-E) has been demonstrated to have a role in AUDs and binge drinking behaviors, and targets $\mu$-opioid receptors in the VTA or $\kappa$-opioid receptors in the NAc (Herz, 1997). Alcohol (EtOH) activates these receptors, which are part of the dopaminergic reward system, potentially starting an addiction cycle (Herz, 1997). Specifically, the BST has been linked to the withdrawal and relapse phases of addiction (Avery et al., 2016). Like $\mathrm{CRH}, \beta-\mathrm{E}$ can regulate the HPA axis. $\mathrm{CRH}$ upregulates the release of $\beta$-E, which binds to $G_{i}$ protein-coupled $\mu$ - and $\delta$-opioid receptors to inhibit the release of $\mathrm{CRH}$ in the $\mathrm{PVH}$ through a negative feedback loop (for review, see Al-Hasani and Bruchas, 2011; Crews et al., 2015). Nentwig et al. (2019) found sex-specific differences in the effects of $\beta$-E on binge drinking behavior, with $\beta$-E-deficient female, but not male, mice consuming more alcohol than both $\beta$-E-deficient male mice and control female mice. $\beta$-E-deficient mice were found to have greater basal Crh expression in the BST, which is reduced upon alcohol consumption to control levels. Increased alcohol consumption in mice with increased Crh expression suggests that the behavior is driven, at least partially, by a desire to reduce stress (Nentwig et al., 2019).

\section{NOREPINEPHRINE}

Norepinephrine (NE), acting through $\alpha$ - and $\beta$-adrenergic receptors (ARs), plays a key role in BST CRH neuron regulation. The main sources of NE input to the BST primarily innervate the BSTv and come from the A1, A2, and A5 brainstem nuclei (Crestani et al., 2013). In the AR family of GPCRs, there are three different types $-\alpha_{1}$ coupled to $G_{\mathrm{q}}$ proteins, $\alpha_{2}$ coupled to $G_{i / o}$ proteins, and $\beta$ coupled to $G_{s}$ proteins-with each type being further divided into three subtypes (Bylund, 2013). Specifically, administering $\alpha_{2 \mathrm{a}}$-ARs agonists to the BST have been shown to reduce anxiety-like responses in rats in fear-potentiated and light-enhanced startle tests (Schweimer et al., 2005) through inhibiting NE signaling (Buffalari et al., 2012). Harris et al. (2018) found this effect to be specific to the BSTd. $\alpha_{2 a}$-AR agonists administered during restraint stress decreased CRH activation in the BST, with sex-specific effects (Fetterly et al., 2019). While $\alpha$-ARs mediate glutamatergic inputs into BST CRH neurons in an inhibitory manner (Fetterly et al., 2019), $\beta$-ARs have been shown to depolarize BST CRH neurons when treated with NE, leading to greater neuronal activation (Snyder et al., 2019). $\beta$-AR 
activation occurs during both stress and EtOH administration, further tying the BST to AUDs (Snyder et al., 2019). Snyder et al. (2019) then go on to propose that NE can alter BST CRH neuron excitability through two distinct pathways: one causing excitatory signaling through $\beta$-ARs that is sensitive to stress and $\mathrm{EtOH}$ exposure, and one causing inhibitory signaling through $\alpha$-ARs that is not. This directly opposes findings from Fetterly et al. (2019) that administration of an $\alpha_{2 \mathrm{a}}$-AR agonist decreased BST $\mathrm{CRH}$ cFos expression during restraint stress, and considering the large overlap of authors between the two papers, this suggests a high level of variability in these stress assays and the need to further delineate the distinct roles of different AR types in response to stress.

\section{DOPAMINE}

Dopamine (DA) signaling in the BST has been linked to dysregulated CRH signaling and reinstatement of drug-seeking behavior (Silberman and Winder, 2013). Many drugs have been found to increase basal DA levels in the BST (Carboni et al., 2000). Main sources of DA to the BST, and in particular the BSTdl, include the VTA, dorsal raphe nucleus, and periaqueductal area (Park et al., 2012). Kash et al. (2008) found that DA application to the BSTdl operated through D1 and D2-like receptors, and enhanced glutamatergic transmission of BST neurons in a CRHR1-dependent manner. More specifically, based on the location of D1 mRNA, DA release may upregulate local CRH release in the BSTov (Daniel and Rainnie, 2016). This demonstrates the importance of BST CRH neuron activation in areas beyond the regulation of anxiety-like behavior, and CRHR1 antagonists remain a potential avenue for the development of therapeutics that help prevent the reinstatement of drugseeking behavior.

\section{ENDOCANNABINOIDS}

Endocannabinoids (eCBs), primarily 2-arachadonylglycerol (2$\mathrm{AG}$ ) and $\mathrm{N}$-arachidonylethanolamine (AEA), are lipid ligands that signal through two different types of $\mathrm{G}_{\mathrm{i} / \mathrm{o}}$ protein-coupled cannabinoid receptors (CBRs), CB1R and CB2R, to help regulate the stress response (for review, see Morena et al., 2016). CB1Rs are widely distributed throughout the brain, and are highly expressed in the BSTd (Puente et al., 2010). Centanni et al. (2019) found greater activation of BSTd CRH neurons following alcohol abstinence in female mice. Treatment with a monoacylglycerol (MAG) lipase inhibitor, which enhances endogenous 2-AG levels, prevented the increase in neuronal activation in the BSTd, specifically through an insular-BSTd circuit (Centanni et al., 2019). Because of the importance of BSTd signaling in the regulation of maladaptive behaviors (Lebow and Chen, 2016), targeting CB1R receptors in that region could comprise a new therapeutic target for the treatment of human mental health disorders (Centanni et al., 2019). However, current research into the link between CRH neuron activation and eCBs in the BST is limited and remains an ongoing area of study.

\section{THERAPEUTIC AND TRANSLATIONAL POTENTIAL}

\section{Current Applications in Deep Brain Stimulation Therapy in Humans}

The role of the BST in sustained fear processing is not limited to rodents. Heightened levels of BST activity in humans have been demonstrated in patients with general anxiety disorder, PTSD, panic disorder, and specific phobias (for review, see Knight and Depue, 2019; Awasthi et al., 2020). While more research into the human BST is needed, there has already been success in treating certain disorders using deep brain stimulation (DBS) to the BST. Luyten et al. (2016) demonstrated in a double-blind crossover study that DBS using electrodes implanted in the BST caused a significant reduction in obsessive-compulsive disorder (OCD) symptoms. While the BST has traditionally been considered outside the scope of OCD neurocircuitry, the success in DBS treatment suggests adaptations to the current model are needed (Luyten, 2020).

Bed nuclei of the stria terminalis DBS was also used to treat a patient with severe MDD and comorbid anorexia nervosa, resulting in significantly reduced scores on depression indices and a reduction in anxiety concerning food and eating behaviors (Blomstedt et al., 2017). In another study, Raymaekers et al. (2017) also found positive effects for the treatment of MDD using BST stimulation. However, sample sizes were limited and more research is needed to more definitely conclude the efficacy of BST DBS for MDD treatment.

\section{Clinical Trials of CRHR1 Antagonists}

Based on the plethora of preclinical evidence implicating the CRH signaling pathway in maladaptive behaviors, several clinical studies have investigated CRHR1 antagonists as potential therapeutic targets for the treatment of anxiety, PTSD, and AUDs. However, they had limited success. Two studies have examined the effects of CRHR1 antagonist verucerfont (formerly GSK561679) on alcohol craving (Schwandt et al., 2016) and PTSD (Dunlop et al., 2017), with both studies finding little effect. However, a study of the CRHR1 antagonist pexacerfont found that the effect of the drug on reducing food cravings was worth further study-although it should be noted that this study was stopped early for legal reasons unrelated to the study safety or outcome (Epstein et al., 2016). While these results might suggest reduced translational potential of CRHR1 antagonists for the treatment of anxiety and other mental health disorders, it is important to consider that the drug administration in humans was not specific to a particular brain region, which is a notable difference from preclinical models. Because injecting drugs directly into the human BST is limited in feasibility due to patient burden and the small size of the BST (Knight and Depue, 2019), it is critical to develop CRHR1 antagonists that are specific to the systems they are targeting. Another limitation of clinical trials is that the experimental design might not exactly match what was being tested in the preclinical model, such as the phase of the addiction model in AUDs (Pomrenze et al., 2017). Careful recruiting of patients to match the conditions of the 
preclinical model as closely as possible may yield better results. In addition, there could be other factors in human neurobiology that influence CRHR1 antagonist effects that are not found in preclinical models. That is why Grillon et al. (2019) recommend using a combination of preclinical models and experimental psychopathology using healthy human volunteers to aid the process of drug discovery and validation, going so far as to recommend adding a new testing criteria between phase I and phase II of clinical trials based on anxiety-potentiated startle (Grillon and Ernst, 2020).

\section{CONCLUSION AND FUTURE DIRECTIONS}

The BST serves as a hub for the regulation of chronic fear responses and other behaviors that can lead to anxiety and mood disorders. The BSTp has mostly anxiolytic effects, largely mediated through CRHR2s. In contrast, the BSTa, particularly the BSTov, has been shown to mediate anxiety-like behavior and is also implicated in mood disorders and drug and alcohol use. In the BSTa, changes to $\mathrm{CRH}$ signaling are critical for these effects. Activation by a wide variety of neurotransmitters and receptors were all demonstrated to affect maladaptive behavior in pre-clinical models. Due to the complicated nature of $\mathrm{CRH}$ interaction with these neurotransmitters, careful experimental design using standardized testing procedures and nuclei classifications will aid in the interpretation of results and enhance reproducibility across labs. Because there are so many neurotransmitters and receptors that are connected to $\mathrm{CRH}$ signaling, targeting $\mathrm{CRH}$ and the CRHRs presents a potential

\section{REFERENCES}

Al-Hasani, R., and Bruchas, M. R. (2011). Molecular mechanisms of opioid receptor-dependent signaling and behavior. Anesthesiology 115, 1363-1381. doi: 10.1097/ALN.0b013e318238bba6

Alheid, G. F., and Heimer, L. (1988). New perspectives in basal forebrain organization of special relevance for neuropsychiatric disorders: The striatopallidal, amygdaloid, and corticopetal components of substantia innominata. Neuroscience 27, 1-39. doi: 10.1016/0306-4522(88)90217-5

Alldredge, B. (2010). Pathogenic involvement of neuropeptides in anxiety and depression. Neuropeptides 44, 215-224. doi: 10.1016/j.npep.2009.12.014

American Psychiatric Association (2013). Diagnostic and Statistical Manual of Mental Disorders, 5th Edn. Washington, DC: APA Publishing.

Avery, S. N., Clauss, J. A., and Blackford, J. U. (2016). The Human BNST: Functional Role in Anxiety and Addiction. Neuropsychopharmacology 41, 126141. doi: 10.1038/npp.2015.185

Awasthi, S., Pan, H., LeDoux, J. E., Cloitre, M., Altemus, M., McEwen, B., et al. (2020). The bed nucleus of the stria terminalis and functionally linked neurocircuitry modulate emotion processing and HPA axis dysfunction in posttraumatic stress disorder. NeuroImage Clin. 28:102442. doi: 10.1016/j.nicl. 2020.102442

Bale, T. L., and Vale, W. W. (2004). CRF and CRF Receptors: Role in Stress Responsivity and Other Behaviors. Annu. Rev. Pharmacol. Toxicol. 44, 525-557. doi: 10.1146/annurev.pharmtox.44.101802.121410

Bartsch, J. C., Jamil, S., Remmes, J., Verma, D., and Pape, H.-C. (2020). Functional deletion of neuropeptide $\mathrm{Y}$ receptors type 2 in local synaptic networks of anteroventral BNST facilitates recall and increases return of fear. Mol. Psychiatr. Preprint. doi: 10.1038/s41380-020-0846-x avenue to cover a broad array of pathways in the treatment of anxiety, mood, and substance use disorders. Considering the high impact those disorders have on society and the economy, and the demonstrated impact of BST treatment on some of these disorders, further research is needed to advance the understanding of how changes in $\mathrm{CRH}$ signaling impacts these disorders. In particular, considering the sexually dimorphic nature of the BST, and the gender bias in pre-clinical research (Ciccocioppo, 2017), more research is needed involving both male and female rodents to help elucidate sex-specific differences in maladaptive behaviors. While previous clinical trials for CRHR1 antagonists have not been successful for the treatment of cravings, given the complexity of BST CRH signaling, there is still room to investigate its role in other disorders, as well as treatments targeting different receptors or pathways linked to $\mathrm{CRH}$ signaling.

\section{AUTHOR CONTRIBUTIONS}

CEY wrote and revised the manuscript. QT provided critical feedback regarding content and structure of the manuscript. Both authors contributed to the article and approved the submitted version.

\section{FUNDING}

The research in the Tong lab is supported by grants from NIH R01DK114279, R21NS108091, R01DK109934, R01DK120858, and DOD W81XWH-19-1-0429. QT is the holder of the Cullen Chair in Molecular Medicine at UT McGovern Medical School.

Betley, J. N., Cao, Z. F. H., Ritola, K. D., and Sternson, S. M. (2013). Parallel, redundant circuit organization for homeostatic control of feeding behavior. Cell 155, 1337-1350. doi: 10.1016/j.cell.2013.11.002

Blomstedt, P., Naesström, M., and Bodlund, O. (2017). Deep brain stimulation in the bed nucleus of the stria terminalis and medial forebrain bundle in a patient with major depressive disorder and anorexia nervosa. Clin. Case Rep. 5, 679-684. doi: 10.1002/ccr3.856

Bota, M., Sporns, O., and Swanson, L. W. (2012). Neuroinformatics analysis of molecular expression patterns and neuron populations in gray matter regions: The rat BST as a rich exemplar. Brain Res. 1450, 174-193. doi: 10.1016/j. brainres.2012.02.034

Boutrel, B., and de Lecea, L. (2008). Addiction and arousal: The hypocretin connection. Physiol. Behav. 93, 947-951. doi: 10.1016/j.physbeh.2007.11.022

Bowen, M. T., Carson, D. S., Spiro, A., Arnold, J. C., and McGregor, I. S. (2011). Adolescent Oxytocin Exposure Causes Persistent Reductions in Anxiety and Alcohol Consumption and Enhances Sociability in Rats. PLoS One 6:e27237. doi: 10.1371/journal.pone.0027237

Buffalari, D. M., Baldwin, C. K., and See, R. E. (2012). Treatment of cocaine withdrawal anxiety with guanfacine: relationships to cocaine intake and reinstatement of cocaine seeking in rats. Psychopharmacology 223, 179-190. doi: 10.1007/s00213-012-2705-1

Bylund, D. B. (2013). “Adrenergic Receptors," in Encyclopedia of Biological Chemistry, 2nd Edn, eds W. J. Lennarz and M. D. Lane (Waltham: Academic Press), 57-60.

Cannella, N., Economidou, D., Kallupi, M., Stopponi, S., Heilig, M., Massi, M., et al. (2009). Persistent Increase of Alcohol-Seeking Evoked by Neuropeptide S: an Effect Mediated by the Hypothalamic Hypocretin System. Neuropsychopharmacology 34, 2125-2134. doi: 10.1038/npp.2009.37 
Carboni, E., Silvagni, A., Rolando, M. T. P., and Di Chiara, G. (2000). Stimulation of \&lt;em\&gt;In Vivo\&lt;/em\&gt; Dopamine Transmission in the Bed Nucleus of Stria Terminalis by Reinforcing Drugs. J. Neurosci. 20:RC102. doi: 10.1523/ JNEUROSCI.20-20-j0002.2000

Carola, V., D’Olimpio, F., Brunamonti, E., Mangia, F., and Renzi, P. (2002). Evaluation of the elevated plus-maze and open-field tests for the assessment of anxiety-related behaviour in inbred mice. Behaviour. Brain Res. 134, 49-57. doi: 10.1016/S0166-4328(01)00452-1

Centanni, S. W., Morris, B. D., Luchsinger, J. R., Bedse, G., Fetterly, T. L., Patel, S., et al. (2019). Endocannabinoid control of the insular-bed nucleus of the stria terminalis circuit regulates negative affective behavior associated with alcohol abstinence. Neuropsychopharmacology 44, 526-537. doi: 10.1038/s41386-0180257-8

Chater, T. E., and Goda, Y. (2014). The role of AMPA receptors in postsynaptic mechanisms of synaptic plasticity. Front. Cell. Neurosci. 8:401. doi: 10.3389/ fncel.2014.00401

Ch'ng, S., Fu, J., Brown, R. M., McDougall, S. J., and Lawrence, A. J. (2018). The intersection of stress and reward: BNST modulation of aversive and appetitive states. Prog. Neuro Psychopharmacol. Biol. Psychiat. 87, 108-125. doi: 10.1016/j. pnpbp.2018.01.005

Ciccocioppo, R. (2017). Grand Challenge in Psychopharmacology: Setting Priorities to Shape a Bright Future. Front. Psychiat. 8:15. doi: 10.3389/fpsyt. 2017.00015

Commons, K. G., Connolley, K. R., and Valentino, R. J. (2003). A Neurochemically Distinct Dorsal Raphe-Limbic Circuit with a Potential Role in Affective Disorders. Neuropsychopharmacology 28, 206-215. doi: 10.1038/sj.npp.1300045

Craske, M. G., Stein, M. B., Eley, T. C., Milad, M. R., Holmes, A., Rapee, R. M., et al. (2017). Anxiety disorders. Nat. Rev. Dis. Primers 3:17024. doi: 10.1038/ nrdp.2017.24

Crestani, C. C., Alves, F. H., Gomes, F. V., Resstel, L. B., Correa, F. M., and Herman, J. P. (2013). Mechanisms in the bed nucleus of the stria terminalis involved in control of autonomic and neuroendocrine functions: a review. Curr. Neuropharmacol. 11, 141-159. doi: 10.2174/1570159X11311020002

Crews, F. T., Sarkar, D. K., Qin, L., Zou, J., Boyadjieva, N., and Vetreno, R. P. (2015). Neuroimmune Function and the Consequences of Alcohol Exposure. Alcohol Res. Curr. Rev. 37, 331-351.

Dabrowska, J., Hazra, R., Ahern, T. H., Guo, J.-D., McDonald, A. J., Mascagni, F., et al. (2011). Neuroanatomical evidence for reciprocal regulation of the corticotrophin-releasing factor and oxytocin systems in the hypothalamus and the bed nucleus of the stria terminalis of the rat: Implications for balancing stress and affect. Psychoneuroendocrinology 36, 1312-1326. doi: 10.1016/j. psyneuen.2011.03.003

Dabrowska, J., Hazra, R., Guo, J., DeWitt, S., and Rainnie, D. (2013). Central CRF neurons are not created equal: phenotypic differences in CRF-containing neurons of the rat paraventricular hypothalamus and the bed nucleus of the stria terminalis. Front. Neurosci. 7:156. doi: 10.3389/fnins.2013.00156

Daldrup, T., Lesting, J., Meuth, P., Seidenbecher, T., and Pape, H.-C. (2016). Neuronal correlates of sustained fear in the anterolateral part of the bed nucleus of stria terminalis. Neurobiol. Learning Memory 131, 137-146. doi: 10.1016/j. nlm.2016.03.020

Daly, E. J., Trivedi, M. H., Janik, A., Li, H., Zhang, Y., Li, X., et al. (2019). Efficacy of Esketamine Nasal Spray Plus Oral Antidepressant Treatment for Relapse Prevention in Patients With Treatment-Resistant Depression: A Randomized Clinical Trial. JAMA Psychiatr. 76, 893-903. doi: 10.1001/jamapsychiatry.2019. 1189

Daniel, S. E., and Rainnie, D. G. (2016). Stress Modulation of Opposing Circuits in the Bed Nucleus of the Stria Terminalis. Neuropsychopharmacol. Offic. Publicat. Am. College Neuropsychopharmacol. 41, 103-125. doi: 10.1038/npp.2015.178

Davis, M., Walker, D. L., Miles, L., and Grillon, C. (2010). Phasic vs Sustained Fear in Rats and Humans: Role of the Extended Amygdala in Fear vs Anxiety. Neuropsychopharmacology 35, 105-135. doi: 10.1038/npp.2009.109

de Vries, G. J., and Miller, M. A. (1999). "Chapter 1.1 Anatomy and function of extrahypothalamic vasopressin systems in the brain," in Progress in Brain Research, eds I. J. A. Urban, J. P. H. Burbach, and D. De Wed (Elsevier), $3-20$.

Dinan, T. G., and Scott, L. V. (2005). Anatomy of melancholia: focus on hypothalamic-pituitary-adrenal axis overactivity and the role of vasopressin. J. Anatomy 207, 259-264. doi: 10.1111/j.1469-7580.2005.00443.x
Dong, H.-W., Petrovich, G. D., Watts, A. G., and Swanson, L. W. (2001). Basic organization of projections from the oval and fusiform nuclei of the bed nuclei of the stria terminalis in adult rat brain. J. Comparat. Neurol. 436, 430-455. doi: $10.1002 /$ cne.1079

Donner, N. C., Davies, S. M., Fitz, S. D., Kienzle, D. M., Shekhar, A., and Lowry, C. A. (2020). Crh receptor priming in the bed nucleus of the stria terminalis (BNST) induces tph2 gene expression in the dorsomedial dorsal raphe nucleus and chronic anxiety. Prog. Neuro Psychopharmacol. Biol. Psychiatr. 96:109730. doi: 10.1016/j.pnpbp.2019.109730

Donner, N. C., Kubala, K. H., Hassell, J. E. Jr., Lieb, M. W., Nguyen, K. T., Heinze, J. D., et al. (2018). Two models of inescapable stress increase tph2 mRNA expression in the anxiety-related dorsomedial part of the dorsal raphe nucleus. Neurobiol. Stress 8, 68-81. doi: 10.1016/j.ynstr.2018.01.003

Dunlop, B. W., Binder, E. B., Iosifescu, D., Mathew, S. J., Neylan, T. C., Pape, J. C., et al. (2017). Corticotropin-Releasing Factor Receptor 1 Antagonism Is Ineffective for Women With Posttraumatic Stress Disorder. Biol. Psychiatr. 82, 866-874. doi: 10.1016/j.biopsych.2017.06.024

Duque-Wilckens, N., Steinman, M. Q., Busnelli, M., Chini, B., Yokoyama, S., Pham, M., et al. (2018). Oxytocin Receptors in the Anteromedial Bed Nucleus of the Stria Terminalis Promote Stress-Induced Social Avoidance in Female California Mice. Biol. Psychiatr. 83, 203-213. doi: 10.1016/j.biopsych.2017.08.024

Duque-Wilckens, N., Steinman, M. Q., Laredo, S. A., Hao, R., Perkeybile, A. M., Bales, K. L., et al. (2016). Inhibition of vasopressin V1a receptors in the medioventral bed nucleus of the stria terminalis has sex- and context-specific anxiogenic effects. Neuropharmacology 110, 59-68. doi: 10.1016/j.neuropharm. 2016.07.018

Ellacott, K. L. J., Morton, G. J., Woods, S. C., Tso, P., and Schwartz, M. W. (2010). Assessment of feeding behavior in laboratory mice. Cell Metab. 12, 10-17. doi: 10.1016/j.cmet.2010.06.001

Epstein, D. H., Kennedy, A. P., Furnari, M., Heilig, M., Shaham, Y., Phillips, K. A., et al. (2016). Effect of the CRF1-receptor antagonist pexacerfont on stress-induced eating and food craving. Psychopharmacology 233, 3921-3932. doi: 10.1007/s00213-016-4424-5

Erb, S., and Stewart, J. (1999). A Role for the Bed Nucleus of the Stria Terminalis, But Not the Amygdala, in the Effects of Corticotropin-Releasing Factor on Stress-Induced Reinstatement of Cocaine Seeking. J. Neurosci. 19:RC35. doi: 10.1523/JNEUROSCI.19-20-j0006.1999

Ferragud, A., Velazquez-Sanchez, C., Minnig, M. A., Sabino, V., and Cottone, P. (2020). Pituitary adenylate cyclase-activating polypeptide (PACAP) modulates dependence-induced alcohol drinking and anxiety-like behavior in male rats. Neuropsychopharmacology 46, 509-518. doi: 10.1038/s41386-020-00904-4

Fetterly, T. L., Basu, A., Nabit, B. P., Awad, E., Williford, K. M., Centanni, S. W., et al. (2019). $\alpha_{2 a}$-Adrenergic Receptor Activation Decreases Parabrachial Nucleus Excitatory Drive onto BNST CRF Neurons and Reduces Their Activity In Vivo. J. Neurosci. 39, 472-484. doi: 10.1523/jneurosci.1035-18.2018

Garcia-Garcia, A. L., Canetta, S., Stujenske, J. M., Burghardt, N. S., Ansorge, M. S., Dranovsky, A., et al. (2018). Serotonin inputs to the dorsal BNST modulate anxiety in a 5-HT1A receptor-dependent manner. Mol. Psychiatr. 23, 1990-1997. doi: 10.1038/mp.2017.165

Ghasemi, M., Phillips, C., Trillo, L., De Miguel, Z., Das, D., and Salehi, A. (2014). The role of NMDA receptors in the pathophysiology and treatment of mood disorders. Neurosci. Biobehav. Rev. 47, 336-358. doi: 10.1016/j.neubiorev.2014. 08.017

Ghazal, P., Ciccocioppo, R., and Ubaldi, M. (2013). Morphine dependence is associated with changes in neuropeptide $S$ receptor expression and function in rat brain. Peptides 46, 6-12. doi: 10.1016/j.peptides.2013.05.001

Giardino, W. J., Eban-Rothschild, A., Christoffel, D. J., Li, S.-B., Malenka, R. C., and de Lecea, L. (2018). Parallel circuits from the bed nuclei of stria terminalis to the lateral hypothalamus drive opposing emotional states. Nat. Neurosci. 21, 1084-1095. doi: 10.1038/s41593-018-0198-x

Gracy, K. N., and Pickel, V. M. (1995). Comparative ultrastructural localization of the NMDAR1 glutamate receptor in the rat basolateral amygdala and bed nucleus of the stria terminalis. J. Comparat. Neurol. 362, 71-85. doi: 10.1002/ cne.903620105

Grillon, C., and Ernst, M. (2020). A way forward for anxiolytic drug development: Testing candidate anxiolytics with anxiety-potentiated startle in healthy humans. Neurosci. Biobehav. Rev. 119, 348-354. doi: 10.1016/j.neubiorev.2020. 09.024 
Grillon, C., Robinson, O. J., Cornwell, B., and Ernst, M. (2019). Modeling anxiety in healthy humans: a key intermediate bridge between basic and clinical sciences. Neuropsychopharmacology 44, 1999-2010. doi: 10.1038/s41386-019-0445-1

Grueter, B. A., and Winder, D. G. (2005). Group II and III Metabotropic Glutamate Receptors Suppress Excitatory Synaptic Transmission in the Dorsolateral Bed Nucleus of the Stria Terminalis. Neuropsychopharmacology 30, 1302-1311. doi: 10.1038/sj.npp.1300672

Grueter, B. A., Gosnell, H. B., Olsen, C. M., Schramm-Sapyta, N. L., Nekrasova, T., Landreth, G. E., et al. (2006). Extracellular-Signal Regulated Kinase 1-Dependent Metabotropic Glutamate Receptor 5-Induced Long-Term Depression in the Bed Nucleus of the Stria Terminalis Is Disrupted by Cocaine Administration. J. Neurosci. 26, 3210-3219. doi: 10.1523/jneurosci.0170-06. 2006

Gungor, N. Z., and Paré, D. (2016). Functional Heterogeneity in the Bed Nucleus of the Stria Terminalis. J. Neurosci. 36:8038. doi: 10.1523/JNEUROSCI.0856-16. 2016

Hammack, S. E., Cheung, J., Rhodes, K. M., Schutz, K. C., Falls, W. A., Braas, K. M., et al. (2009a). Chronic stress increases pituitary adenylate cyclaseactivating peptide (PACAP) and brain-derived neurotrophic factor (BDNF) mRNA expression in the bed nucleus of the stria terminalis (BNST): Roles for PACAP in anxiety-like behavior. Psychoneuroendocrinology 34, 833-843. doi: 10.1016/j.psyneuen.2008.12.013

Hammack, S. E., Guo, J.-D., Hazra, R., Dabrowska, J., Myers, K. M., and Rainnie, D. G. (2009b). The response of neurons in the bed nucleus of the stria terminalis to serotonin: Implications for anxiety. Prog. Neuro Psychopharmacol. Biol. Psychiatry 33, 1309-1320. doi: 10.1016/j.pnpbp.2009.05.013

Hammack, S. E., Mania, I., and Rainnie, D. G. (2007). Differential expression of intrinsic membrane currents in defined cell types of the anterolateral bed nucleus of the stria terminalis. J. Neurophysiol. 98, 638-656. doi: 10.1152/jn. 00382.2007

Harris, N. A., Isaac, A. T., Günther, A., Merkel, K., Melchior, J., Xu, M., et al. (2018). Dorsal BNST $\alpha_{2 \mathrm{a}}$-Adrenergic Receptors Produce HCN-Dependent Excitatory Actions That Initiate Anxiogenic Behaviors. J. Neurosci. 38, 8922-8942. doi: 10.1523/jneurosci.0963-18.2018

Henckens, M. J. A. G., Printz, Y., Shamgar, U., Dine, J., Lebow, M., Drori, Y., et al. (2017). CRF receptor type 2 neurons in the posterior bed nucleus of the stria terminalis critically contribute to stress recovery. Mol. Psychiatr. 22, 1691-1700. doi: $10.1038 / \mathrm{mp} .2016 .133$

Hernando, F., Schoots, O., Lolait, S. J., and Burbach, J. P. (2001). Immunohistochemical localization of the vasopressin V1b receptor in the rat brain and pituitary gland: anatomical support for its involvement in the central effects of vasopressin. Endocrinology 142, 1659-1668. doi: 10.1210/endo.142.4.8067

Herz, A. (1997). Endogenous opioid systems and alcohol addiction. Psychopharmacology 129, 99-111. doi: 10.1007/s002130050169

Higuchi, H. (2012). Molecular analysis of central feeding regulation by neuropeptide Y (NPY) neurons with NPY receptor small interfering RNAs (siRNAs). Neurochem. Int. 61, 936-941. doi: 10.1016/j.neuint.2012.02.029

Hillhouse, E. W., and Grammatopoulos, D. K. (2006). The Molecular Mechanisms Underlying the Regulation of the Biological Activity of Corticotropin-Releasing Hormone Receptors: Implications for Physiology and Pathophysiology. Endocr. Rev. 27, 260-286. doi: 10.1210/er.2005-0034

Hu, P., Liu, J., Maita, I., Kwok, C., Gu, E., Gergues, M. M., et al. (2020). Chronic Stress Induces Maladaptive Behaviors by Activating Corticotropin-Releasing Hormone Signaling in the Mouse Oval Bed Nucleus of the Stria Terminalis. J. Neurosci. 40, 2519-2537. doi: 10.1523/jneurosci.2410-19.2020

Janeček, M., and Dabrowska, J. (2019). Oxytocin facilitates adaptive fear and attenuates anxiety responses in animal models and human studies-potential interaction with the corticotropin-releasing factor (CRF) system in the bed nucleus of the stria terminalis (BNST). Cell Tissue Res. 375, 143-172. doi: 10.1007/s00441-018-2889-8

Ju, G., and Swanson, L. W. (1989). Studies on the cellular architecture of the bed nuclei of the stria terminalis in the rat: I. cytoarchitecture. J. Comparat. Neurol. 280, 587-602. doi: 10.1002/cne.902800409

Ju, G., Swanson, L. W., and Simerly, R. B. (1989). Studies on the cellular architecture of the bed nuclei of the stria terminalis in the rat: II. chemoarchitecture. J. Comparat. Neurol. 280, 603-621. doi: 10.1002/cne. 902800410
Kash, T. L., Nobis, W. P., Matthews, R. T., and Winder, D. G. (2008). Dopamine Enhances Fast Excitatory Synaptic Transmission in the Extended Amygdala by a CRF-R1-Dependent Process. J. Neurosci. 28:13856. doi: 10.1523/JNEUROSCI. 4715-08.2008

Kash, T. L., Pleil, K. E., Marcinkiewcz, C. A., Lowery-Gionta, E. G., Crowley, N., Mazzone, C., et al. (2015). Neuropeptide regulation of signaling and behavior in the BNST. Molecul. Cells 38, 1-13. doi: 10.14348/molcells.2015.2261

Kasten, C. R., Carzoli, K. L., Sharfman, N. M., Henderson, T., Holmgren, E. B., Lerner, M. R., et al. (2020). Adolescent alcohol exposure produces sex differences in negative affect-like behavior and group I mGluR BNST plasticity. Neuropsychopharmacology 45, 1306-1315. doi: 10.1038/s41386-020-0670-7

Kim, S.-Y., Adhikari, A., Lee, S. Y., Marshel, J. H., Kim, C. K., Mallory, C. S., et al. (2013). Diverging neural pathways assemble a behavioural state from separable features in anxiety. Nature 496, 219-223. doi: 10.1038/nature12018

King, S. B., Lezak, K. R., O’Reilly, M., Toufexis, D. J., Falls, W. A., Braas, K., et al. (2017). The Effects of Prior Stress on Anxiety-Like Responding to Intra-BNST Pituitary Adenylate Cyclase Activating Polypeptide in Male and Female Rats. Neuropsychopharmacology 42, 1679-1687. doi: 10.1038/npp.2017.16

Knight, L. K., and Depue, B. E. (2019). New Frontiers in Anxiety Research: The Translational Potential of the Bed Nucleus of the Stria Terminalis. Front. Psychiatr. 10:510. doi: 10.3389/fpsyt.2019.00510

Kocho-Schellenberg, M., Lezak, K. R., Harris, O. M., Roelke, E., Gick, N., Choi, I., et al. (2014). PACAP in the BNST Produces Anorexia and Weight Loss in Male and Female Rats. Neuropsychopharmacology 39, 1614-1623. doi: 10.1038/npp. 2014.8

Koob, G. F., and Greenwell, T. N. (2004). Neuropeptide S: A Novel Activating Anxiolytic? Neuron 43, 441-442. doi: 10.1016/j.neuron.2004.08.007

Kormos, V., and Gaszner, B. (2013). Role of neuropeptides in anxiety, stress, and depression: From animals to humans. Neuropeptides 47, 401-419. doi: 10.1016/ j.npep.2013.10.014

Kozicz, T., Vigh, S., and Arimura, A. (1998). The source of origin of PACAP- and VIP-immunoreactive fibers in the laterodorsal division of the bed nucleus of the stria terminalis in the rat. Brain Res. 810, 211-219. doi: 10.1016/S0006-8993(98) 00692-1

Krishnan, V., and Nestler, E. J. (2011). Animal models of depression: molecular perspectives. Curr. Topics Behav. Neurosci. 7, 121-147. doi: 10.1007/7854_ 2010_108

Lebow, M. A., and Chen, A. (2016). Overshadowed by the amygdala: the bed nucleus of the stria terminalis emerges as key to psychiatric disorders. Mol. Psychiatr. 21, 450-463. doi: 10.1038/mp.2016.1

Lebow, M., Neufeld-Cohen, A., Kuperman, Y., Tsoory, M., Gil, S., and Chen, A. (2012). Susceptibility to PTSD-Like Behavior Is Mediated by CorticotropinReleasing Factor Receptor Type 2 Levels in the Bed Nucleus of the Stria Terminalis. J. Neurosci. 32, 6906-6916. doi: 10.1523/jneurosci.4012-11.2012

LeDoux, J. E., and Pine, D. S. (2016). Using Neuroscience to Help Understand Fear and Anxiety: A Two-System Framework. Am. J. Psychiatry 173, 1083-1093. doi: 10.1176/appi.ajp.2016.16030353

Lee, H.-J., Macbeth, A. H., Pagani, J. H., and Young, W. S. III (2009). Oxytocin: the great facilitator of life. Prog. Neurobiol. 88, 127-151. doi: 10.1016/j.pneurobio. 2009.04.001

Leeuwen, F., and Caffé, R. (1983). Immunoreactive vasopressin cell bodies in the rat bed nucleus of the stria terminalis. Cell Tissue Res. 228, 525-534. doi: 10.1007/BF00211473

Lein, E. S., Hawrylycz, M. J., Ao, N., Ayres, M., Bensinger, A., Bernard, A., et al. (2007). Genome-wide atlas of gene expression in the adult mouse brain. Nature 445, 168-176. doi: 10.1038/nature05453

Leonard, S. K., and Ring, R. H. (2011). Immunohistochemical localization of the neuropeptide S receptor in the rat central nervous system. Neuroscience 172, 153-163. doi: 10.1016/j.neuroscience.2010.10.020

Levita, L., Hammack, S. E., Mania, I., Li, X. Y., Davis, M., and Rainnie, D. G. (2004). 5-hydroxytryptaminela-likereceptor activation in the bed nucleus of the stria terminalis: Electrophysiological and behavioral studies. Neuroscience 128, 583-596. doi: 10.1016/j.neuroscience.2004.06.037

Lowry, C. A., Rodda, J. E., Lightman, S. L., and Ingram, C. D. (2000). CorticotropinReleasing Factor Increases In Vitro Firing Rates of Serotonergic Neurons in the Rat Dorsal Raphe Nucleus: Evidence for Activation of a Topographically Organized Mesolimbocortical Serotonergic System. J. Neurosci. 20, 7728-7736. doi: 10.1523/jneurosci.20-20-07728.2000 
Luyten, L. (2020). The Bed Nucleus of the Stria Terminalis: Translational Deep Brain Stimulation to Reduce Anxiety. Neuroscientist 26, 278-284. doi: 10.1177/ 1073858419898381

Luyten, L., Hendrickx, S., Raymaekers, S., Gabriëls, L., and Nuttin, B. (2016). Electrical stimulation in the bed nucleus of the stria terminalis alleviates severe obsessive-compulsive disorder. Mol. Psychiatry 21, 1272-1280. doi: 10.1038/ mp.2015.124

Marcinkiewcz, C. A., Bierlein-De, La Rosa, G., Dorrier, C. E., McKnight, M., DiBerto, J. F., et al. (2019). Sex-Dependent Modulation of Anxiety and Fear by 5 -HT1A Receptors in the Bed Nucleus of the Stria Terminalis. ACS Chem. Neurosci. 10, 3154-3166. doi: 10.1021/acschemneuro.8b00594

Marcinkiewcz, C. A., Mazzone, C. M., D’Agostino, G., Halladay, L. R., Hardaway, J. A., DiBerto, J. F., et al. (2016). Serotonin engages an anxiety and fearpromoting circuit in the extended amygdala. Nature 537, 97-101. doi: 10.1038/ nature 19318

Misra, S., Murthy, K. S., Zhou, H., and Grider, J. R. (2004). Coexpression of $\mathrm{Y}_{1}, \mathrm{Y}_{2}$, and $\mathrm{Y}_{4}$ Receptors in Smooth Muscle Coupled to Distinct Signaling Pathways. J. Pharmacol. Exp. Therapeut. 311, 1154-1162. doi: 10.1124/jpet.104.071415

Moga, M. M., and Saper, C. B. (1994). Neuropeptide-immunoreactive neurons projecting to the paraventricular hypothalamic nucleus in the rat. J. Comparat. Neurol. 346, 137-150. doi: 10.1002/cne.903460110

Morena, M., Patel, S., Bains, J. S., and Hill, M. N. (2016). Neurobiological Interactions Between Stress and the Endocannabinoid System. Neuropsychopharmacology 41, 80-102. doi: 10.1038/npp.2015.166

Nentwig, T. B., Wilson, D. E., Rhinehart, E. M., and Grisel, J. E. (2019). Sex differences in binge-like EtOH drinking, corticotropin-releasing hormone and corticosterone: effects of $\beta$-endorphin. Addict. Biol. 24, 447-457. doi: 10.1111/ adb. 12610

Pañeda, C., Huitron-Resendiz, S., Frago, L. M., Chowen, J. A., Picetti, R., de Lecea, L., et al. (2009). Neuropeptide S reinstates cocaine-seeking behavior and increases locomotor activity through corticotropin-releasing factor receptor 1 in mice. J. Neurosci. 29, 4155-4161. doi: 10.1523/JNEUROSCI.5256-08.2009

Park, J., Wheeler, R. A., Fontillas, K., Keithley, R. B., Carelli, R. M., and Wightman, R. M. (2012). Catecholamines in the Bed Nucleus of the Stria Terminalis Reciprocally Respond to Reward and Aversion. Biol. Psychiatr. 71, 327-334. doi: 10.1016/j.biopsych.2011.10.017

Pedragosa Badia, X., Stichel, J., and Beck-Sickinger, A. (2013). Neuropeptide Y receptors: how to get subtype selectivity. Front. Endocrinol. 4:5. doi: 10.3389/ fendo.2013.00005

Pisegna, J. R., and Wank, S. A. (1996). Cloning and Characterization of the Signal Transduction of Four Splice Variants of the Human Pituitary Adenylate Cyclase Activating Polypeptide Receptor: EVIDENCE FOR DUAL COUPLING TO ADENYLATE CYCLASE AND PHOSPHOLIPASE C. J. Biol. Chem. 271, 17267-17274.

Pleil, K. E., Rinker, J. A., Lowery-Gionta, E. G., Mazzone, C. M., McCall, N. M., Kendra, A. M., et al. (2015). NPY signaling inhibits extended amygdala CRF neurons to suppress binge alcohol drinking. Nat. Neurosci. 18, 545-552. doi: 10.1038/nn.3972

Pomrenze, M. B., Fetterly, T. L., Winder, D. G., and Messing, R. O. (2017). The Corticotropin Releasing Factor Receptor 1 in Alcohol Use Disorder: Still a Valid Drug Target? Alcohol. Clin. Exp. Res. 41, 1986-1999. doi: 10.1111/acer.13507

Pomrenze, M. B., Tovar-Diaz, J., Blasio, A., Maiya, R., Giovanetti, S. M., Lei, K., et al. (2019). A Corticotropin Releasing Factor Network in the Extended Amygdala for Anxiety. J. Neurosci. 39, 1030-1043. doi: 10.1523/jneurosci.214318.2018

Popova, V., Daly, E. J., Trivedi, M., Cooper, K., Lane, R., Lim, P., et al. (2019). Efficacy and Safety of Flexibly Dosed Esketamine Nasal Spray Combined With a Newly Initiated Oral Antidepressant in Treatment-Resistant Depression: A Randomized Double-Blind Active-Controlled Study. Am. J. Psychiatry 176, 428-438. doi: 10.1176/appi.ajp.2019.19020172

Puente, N., Elezgarai, I., Lafourcade, M., Reguero, L., Marsicano, G., Georges, F., et al. (2010). Localization and function of the cannabinoid CB1 receptor in the anterolateral bed nucleus of the stria terminalis. PLoS One 5:e8869-e8869. doi: 10.1371/journal.pone.0008869

Quentin, E., Belmer, A., and Maroteaux, L. (2018). Somato-Dendritic Regulation of Raphe Serotonin Neurons; A Key to Antidepressant Action. Front. Neurosci. 12:982. doi: 10.3389/fnins.2018.00982
Raymaekers, S., Luyten, L., Bervoets, C., Gabriëls, L., and Nuttin, B. (2017). Deep brain stimulation for treatment-resistant major depressive disorder: a comparison of two targets and long-term follow-up. Translat. Psychiatr. 7, 1251-1251e. doi: 10.1038/tp.2017.66

Sahuque, L. L., Kullberg, E. F., McGeehan, A. J., Kinder, J. R., Hicks, M. P., Blanton, M. G., et al. (2006). Anxiogenic and aversive effects of corticotropinreleasing factor $(\mathrm{CRF})$ in the bed nucleus of the stria terminalis in the rat: role of CRF receptor subtypes. Psychopharmacology 186, 122-132. doi: 10.1007/ s00213-006-0362-y

Salimando, G. J., Hyun, M., Boyt, K. M., and Winder, D. G. (2020). BNST GluN2D-Containing NMDA Receptors Influence Anxiety- and Depressive-like Behaviors and ModulateCell-Specific Excitatory/Inhibitory Synaptic Balance. J. Neurosci. 40, 3949-3968. doi: 10.1523/jneurosci.0270-20.2020

Sanchez-Bautista, S., and Nicolas, F. E. (2013). Recent patents concerning modulators of protein kinase C. Recent Pat. DNA Gene Seq. 7, 74-81. doi: $10.2174 / 1872215611307010011$

Schatzberg, A. F. (2019). A Word to the Wise About Intranasal Esketamine. Am. J. Psychiatr. 176, 422-424. doi: 10.1176/appi.ajp.2019.19040423

Schwandt, M. L., Cortes, C. R., Kwako, L. E., George, D. T., Momenan, R., Sinha, R., et al. (2016). The CRF1 Antagonist Verucerfont in Anxious AlcoholDependent Women: Translation of Neuroendocrine, But not of Anti-Craving Effects. Neuropsychopharmacology 41, 2818-2829. doi: 10.1038/npp.2016.61

Schweimer, J., Fendt, M., and Schnitzler, H.-U. (2005). Effects of clonidine injections into the bed nucleus of the stria terminalis on fear and anxiety behavior in rats. Eur. J. Pharmacol. 507, 117-124. doi: 10.1016/j.ejphar.2004. 11.044

Shackman, A. J., and Fox, A. S. (2016). Contributions of the Central Extended Amygdala to Fear and Anxiety. J. Neurosci. 36, 8050-8063. doi: 10.1523/ jneurosci.0982-16.2016

Silberman, Y., and Winder, D. (2013). Emerging Role for Corticotropin Releasing Factor Signaling in the Bed Nucleus of the Stria Terminalis at the Intersection of Stress and Reward. Front. Psychiatry 4:42. doi: 10.3389/fpsyt.2013.00042

Snyder, A. E., Salimando, G. J., Winder, D. G., and Silberman, Y. (2019). Chronic Intermittent Ethanol and Acute Stress Similarly Modulate BNST CRF Neuron Activity via Noradrenergic Signaling. Alcoholism Clin. Exp. Res. 43, 1695-1701. doi: 10.1111 /acer. 14118

Soya, S., and Sakurai, T. (2020). Evolution of Orexin Neuropeptide System: Structure and Function. Front. Neurosci. 14:691. doi: 10.3389/fnins.2020.00691

Steinman, M. Q., Duque-Wilckens, N., and Trainor, B. C. (2019). Complementary Neural Circuits for Divergent Effects of Oxytocin: Social Approach Versus Social Anxiety. Biol. Psychiatr. 85, 792-801. doi: 10.1016/j.biopsych.2018.10.008

Swanson, L. W. (2004). Brain Maps: Structure of the Rat Brain, A Laboratory Guide with Printed and Electronic Templates for Data, Models and Schematics. Amsterdam: Elsevier.

Thorsell, A., Rimondini, R., and Heilig, M. (2002). Blockade of central neuropeptide Y (NPY) Y2 receptors reduces ethanol self-administration in rats. Neurosci. Lett. 332, 1-4. doi: 10.1016/S0304-3940(02)00904-7

US Food and Drug Administration (2019). FDA approves new nasal spray medication for treatment-resistant depression; available only at a certified doctor's office or clinic. Washington, D.C: US Food and Drug Administration.

Van Pett, K., Viau, V., Bittencourt, J. C., Chan, R. K. W., Li, H.-Y., Arias, C., et al. (2000). Distribution of mRNAs encoding CRF receptors in brain and pituitary of rat and mouse. J. Comparat. Neurol. 428, 191-212. doi: 10.1002/ 1096-9861(20001211)428:2<191::AID-CNE1<3.0.CO;2-U

Vaughan, J., Donaldson, C., Bittencourt, J., Perrin, M. H., Lewis, K., Sutton, S., et al. (1995). Urocortin, a mammalian neuropeptide related to fish urotensin I and to corticotropin-releasing factor. Nature 378, 287-292. doi: 10.1038/378 $287 \mathrm{a} 0$

Veinante, P., Stoeckel, M. E., and Freund-Mercier, M. J. (1997). GABAand peptide-immunoreactivities co-localize in the rat central extended amygdala. Neuroreport 8, 2985-2989. doi: 10.1097/00001756-19970908000035

Ventura-Silva, A. P., Borges, S., Sousa, N., Rodrigues, A. J., and Pêgo, J. M. (2020). Amygdalar corticotropin-releasing factor mediates stress-induced anxiety. Brain Res. 1729:146622. doi: 10.1016/j.brainres.2019.146622

Vranjkovic, O., Pina, M., Kash, T. L., and Winder, D. G. (2017). The bed nucleus of the stria terminalis in drug-associated behavior and affect: A circuit-based 
perspective. Neuropharmacology 122, 100-106. doi: 10.1016/j.neuropharm. 2017.03.028

Walker, D. L., and Davis, M. (1997). Double Dissociation between the Involvement of the Bed Nucleus of the Stria Terminalis and the Central Nucleus of the Amygdala in Startle Increases Produced by Conditioned versus Unconditioned Fear. J. Neurosci. 17, 9375-9383. doi: 10.1523/jneurosci.17-23-09375. 1997

Walker, D. L., Toufexis, D. J., and Davis, M. (2003). Role of the bed nucleus of the stria terminalis versus the amygdala in fear, stress, and anxiety. Eur. J. Pharmacol. 463, 199-216. doi: 10.1016/S0014-2999(03)01282-2

Wang, Y., Kim, J., Schmit, M. B., Cho, T. S., Fang, C., and Cai, H. (2019). A bed nucleus of stria terminalis microcircuit regulating inflammation-associated modulation of feeding. Nat. Commun. 10:2769. doi: 10.1038/s41467-019$10715-x$

Xu, Y.-L., Gall, C. M., Jackson, V. R., Civelli, O., and Reinscheid, R. K. (2007). Distribution of neuropeptide S receptor mRNA and neurochemical characteristics of neuropeptide S-expressing neurons in the rat brain. J. Comparat. Neurol. 500, 84-102. doi: 10.1002/cne.21159
Xu, Y.-L., Reinscheid, R. K., Huitron-Resendiz, S., Clark, S. D., Wang, Z., Lin, S. H., et al. (2004). Neuropeptide S: A Neuropeptide Promoting Arousal and Anxiolytic-like Effects. Neuron 43, 487-497. doi: 10.1016/j.neuron.2004.08.005

Zheng, W., Cai, D.-B., Xiang, Y.-Q., Zheng, W., Jiang, W.-L., Sim, K., et al. (2020). Adjunctive intranasal esketamine for major depressive disorder: A systematic review of randomized double-blind controlled-placebo studies. J. Affect. Disord. 265, 63-70. doi: 10.1016/j.jad.2020.01.002

Conflict of Interest: The authors declare that the research was conducted in the absence of any commercial or financial relationships that could be construed as a potential conflict of interest.

Copyright (c) 2021 Young and Tong. This is an open-access article distributed under the terms of the Creative Commons Attribution License (CC BY). The use, distribution or reproduction in other forums is permitted, provided the original author(s) and the copyright owner(s) are credited and that the original publication in this journal is cited, in accordance with accepted academic practice. No use, distribution or reproduction is permitted which does not comply with these terms. 